\title{
BMJ Open Risk of asthma in children diagnosed with bronchiolitis during infancy: protocol of a longitudinal cohort study linking emergency department-based clinical data to provincial health administrative databases
}

\author{
Kawsari Abdullah (D , ,,2 Deshayne B Fell, ${ }^{1,2,3}$ Dhenuka Radhakrishnan, ${ }^{1,2,4}$ \\ Steven Hawken, ${ }^{2,5}$ David W Johnson, ${ }^{6,7}$ Piush Mandhane, ${ }^{8}$ Teresa To (D) ,2,9 \\ Gary Joubert, ${ }^{10}$ Amy C Plint,,${ }^{1,4}$ for Pediatric Emergency Research Canada
}

To cite: Abdullah K, Fell DB, Radhakrishnan D, et al. Risk of asthma in children diagnosed with bronchiolitis during infancy: protocol of a longitudinal cohort study linking emergency department-based clinical data to provincial health administrative databases. BMJ Open 2021;11:e048823. doi:10.1136/ bmjopen-2021-048823

- Prepublication history and supplemental material for this paper is available online. To view these files, please visit the journal online (http://dx.doi org/10.1136/bmjopen-2021048823).

Received 11 January 2021 Revised 11 March 2021 Accepted 07 April 2021

D) Check for updates

(c) Author(s) (or their employer(s)) 2021. Re-use permitted under CC BY-NC. No commercial re-use. See rights and permissions. Published by BMJ.

For numbered affiliations see end of article.

Correspondence to Dr Kawsari Abdullah; KAbdullah@cheo.on.ca; kawsari74@yahoo.com

\section{ABSTRACT}

Introduction The Canadian Bronchiolitis Epinephrine Steroid Trial (CanBEST) and the Bronchiolitis Severity Cohort (BSC) study enrolled infants with bronchiolitis during the first year of life. The CanBEST trial suggested that treatment of infants with a combined therapy of highdose corticosteroids and nebulised epinephrine reduced the risk of admission to hospital. Our study aims to-(1) quantify the risk of developing asthma by age 5 and 10 years in children treated with high-dose corticosteroid and epinephrine for bronchiolitis during infancy, (2) identify risk factors associated with development of asthma in children with bronchiolitis during infancy, (3) develop asthma prediction models for children diagnosed with bronchiolitis during infancy.

Methods and analysis We propose a longitudinal cohort study in which we will link data from the CanBEST (ISRCTN56745572, post-results) and BSC study with routinely collected data from provincial health administrative databases. Our outcome is asthma incidence measured using a validated health administrative data algorithm. Primary exposure will be treatment with a combined therapy of high-dose corticosteroids and nebulised epinephrine for bronchiolitis. Covariates will include type of viral pathogen, disease severity, medication use, maternal, prenatal, postnatal and demographic factors and variables related to health service utilisation for acute lower respiratory tract infection. The risk associated with development of asthma in children treated with high-dose corticosteroid and epinephrine for bronchiolitis will be assessed using multivariable Cox proportional hazards regression models. Prediction models will be developed using multivariable logistic regression analysis and internally validated using a bootstrap approach.

Ethics and dissemination Our study has been approved by the ethics board of all four participating sites of the CanBEST and BSC study. Finding of the study will be disseminated to the academic community and relevant stakeholders through conferences and peer-reviewed publications.
Strengths and limitations of this study

- Our study provides an opportunity to specifically examine whether treatment of infants with bronchiolitis with combined high-dose corticosteroids and nebulised epinephrine reduces the risk of future asthma.

- Linkage of data from clinical studies to health service utilisation data may provide objective, prospectively collected measures and outcomes that are free of recall bias and minimise loss to follow-up and data missingness.

- Diagnosis of asthma using health service utilisation data is a proxy method, but we will use a validated health-administrative algorithm for the detection of asthma.

\section{INTRODUCTION}

A multitude of controlled follow-up studies has established that viral bronchiolitis during infancy is associated with on-going respiratory morbidity. Infants with bronchiolitis have an increased risk of developing wheezeassociated disorders, including asthma, in later life. ${ }^{12}$ Respiratory syncytial virus (RSV) is the most common aetiological agent detected in infants with bronchiolitis. ${ }^{3}$ Studies have shown $20 \%-54 \%$ of infants with bronchiolitis develop asthma. ${ }^{4-12} \mathrm{~A}$ multivariate evaluation of possible risk factors for asthma showed that RSV bronchiolitis during infancy had the highest independent OR for asthma (OR: $12.7,95 \%$ CI 3.4 to 47.1 ). ${ }^{1}$ However, a more recent systematic review has reported that this association may not be causal. ${ }^{13}$ This association appears most pronounced during the first 5 years of life but may extend up to 
10 years of age. ${ }^{14-16}$ The mechanism through which RSV contributes to asthma is not fully understood but appears to relate to the viral injury, disease severity, pre-existing abnormal lung function, genetic susceptibility, altered immunology and environmental factors. ${ }^{1}{ }^{13}$

A number of risk factors have been found to be associated with the development of asthma among children with a history of bronchiolitis in early life. These include the child's clinical course of bronchiolitis (severity of illness and viral pathogen), prenatal (maternal asthma control and smoking during pregnancy) and postnatal factors (prematurity, congenital heart disease, pre-existing impaired lung function, personal history of atopy) and early childhood (breastfeeding, daycare attendance), parental (family history of atopy and asthma), household (moisture, dust, mite, tobacco smoke) and demographic factors (men, lower socioeconomic status, immigrant status). ${ }^{121718}$ In addition to these, the pattern of health service utilisation by children during their preschool years and the services they receive for prevention of respiratory disorders during the first 2 years of life may also be associated with later development of asthma. ${ }^{19}$

It has been postulated that the immune response followed by viral bronchiolitis may induce long-lasting detrimental effects and contribute to postbronchiolitis wheezing and asthma. ${ }^{20-23}$ For example, severe RSV bronchiolitis in young infant may shift the T-helper (Th)1/ Th2 balance in favour of a Th2 cytokine pattern, leading to development of allergic sensitisation and persistent asthma. ${ }^{424}$ As a result, it has been suggested that immunemodulating drugs such as corticosteroids might prevent the development of asthma. ${ }^{25}{ }^{26}$ Most follow-up studies in bronchiolitis, however, have found no association between corticosteroid use and the degree of respiratory sequelae after bronchiolitis. ${ }^{25-28}$ However, these studies primarily examined admitted patients who may have had more severe disease and were at a later stage in the disease process. The majority of studies also had relatively small samples and were likely underpowered to detect possible beneficial effects. Importantly, corticosteroids alone appear to have no immediate benefit in the treatment of bronchiolitis $^{27-29}$ and, thus, are not recommended for the treatment of bronchiolitis. ${ }^{30-33}$

The Canadian Bronchiolitis Epinephrine Steroid Trial $(\text { CanBEST })^{29}$ and the Bronchiolitis Severity Cohort $(\mathrm{BSC})^{34}$ study enrolled infants with bronchiolitis during their first year of life. These studies have established a bronchiolitis cohort where detailed clinical data, including the management and clinical outcomes for infants with bronchiolitis, are known. Results from the CanBEST trial suggested that the combined therapy of high-dose corticosteroids and nebulised epinephrine may reduce admissions to hospital for children with bronchiolitis through a synergistic effect between the two medications. ${ }^{29}$ Basic science evidence supports a synergistic effect of corticosteroid and epinephrine in modulating the immune system through several mechanisms: (1) $\beta_{2}$-adrenoceptor agonists synergistically upregulate mRNA production of anti-inflammatory genes by enhanced translocation of the glucocorticoid receptor into the nucleus ${ }^{35} 36$ and (2) corticosteroids enhance and markedly extend upregulation of mRNA for regulation of G-protein signalling 2 by $B_{2}$-adrenoceptor agonists. ${ }^{37}$ Clinical studies in asthma have also demonstrated that combined administration of high-dose corticosteroid and epinephrine results in anti-inflammatory and bronchoprotective effects that are unachievable by either drug alone. ${ }^{36}{ }^{37}$ Given the potential benefit seen in the acute management of bronchiolitis and the clinical and basic science evidence of true synergy between betaagonists and corticosteroids, it is important to examine whether any longer term benefit of such treatment in acute phase bronchiolitis exists.

Early identification of children who later develop asthma may improve their quality of life by appropriate preventive measures, regular monitoring and appropriate drug treatment. ${ }^{38}$ Predictive models have been shown to help physicians to identify asthma, particularly in children under 5 years. ${ }^{39-41}$ However, the majority of these prediction models have targeted children in the general population rather than children with bronchiolitis per se. ${ }^{4142}$ There is evidence to suggest that simple clinical parameters, such as-age, sex, history of atopy, family history of asthma and early frequent wheezing during the first 3 years of life, can identify children at high risk of developing asthma by age 6 , specifically in children diagnosed with RSV bronchiolitis during infancy. ${ }^{43}$ In addition, the level of healthcare utilisation during the bronchiolitis episode has been found to correlate with the risk of subsequent asthma, with the greatest risk of asthma following bronchiolitis hospitalisation. ${ }^{44-46} \mathrm{~A}$ study has shown that children who develop asthma have high intensity health service utilisation during preschool years. ${ }^{47}$

Our proposed study aims to link CanBEST and BSC data to provincial health administrative databases (HAD). The unique combination of these data sources can provide objective, prospectively collected measures and outcomes that are free of recall bias. Moreover, it minimises loss to follow-up and data missingness, as individuals are consistently followed in HAD. This study will allow us to examine the long-term effect of high-dose corticosteroid and epinephrine treatment on the respiratory health of children diagnosed with bronchiolitis during infancy as well as develop the most parsimonious asthma prediction models specifically for children diagnosed with bronchiolitis during infancy. Our three objectives are:

Objective 1: to quantify the risk of developing asthma by age 5 and 10 years in children treated with high-dose corticosteroid and epinephrine for bronchiolitis during infancy.

Objective 2: to identify risk factors associated with the development of asthma in children diagnosed with bronchiolitis during infancy.

Objective 3: to develop asthma prediction models for children diagnosed with bronchiolitis during infancy. 


\section{METHODS}

\section{Study design}

We will conduct a longitudinal cohort study by linking clinical data from two emergency department (ED)-based bronchiolitis studies (CanBEST and BSC) with routinely collected HAD.

\section{Study population}

Our study will include children recruited from Ontario and Alberta sites of the CanBEST and BSC study (all sites are members of the research collaboration Pediatrics Emergency Research Canada). CanBEST and BSC study recruited participants from paediatric EDs from 2004 to 2007 (CanBEST, N=720; BSCS, N=724). Inclusion criteria for this study are children who were diagnosed with bronchiolitis at age $\leq 12$ months and participated in the CanBEST or BSC study (inclusion and exclusion details of CanBEST and BSC study available elsewhere). ${ }^{29} 34$ Exclusion criteria are subjects without a valid Ontario or Alberta health card number for data linkage, subjects without an $\mathrm{ON}$ or $\mathrm{AB}$ residence code (at the time of enrolment into the trial) or those who could not be linked.

\section{Data sources}

Clinical data: a bronchiolitis cohort will be created by pooling data from the CanBEST and BSC study. CanBEST was a multicentre, double-blind, placebo-controlled randomised trial in which infants with bronchiolitis were enrolled from nine paediatric EDs across Canada. ${ }^{29}$ For our proposed study, data from four sites in two provinces will be used and linked (total sample size 720; Ontario sites: Children's Hospital of Eastern Ontario, Ottawa, and Children's Hospital London Health Sciences Centre, London; Alberta sites: Alberta Children's Hospital, Calgary and Stollery Children's Hospital, Edmonton). In CanBEST, participants were randomly assigned to one of four intervention groups. Group 1: epinephrine-highdose oral corticosteroid, group 2: epinephrine, group 3: high-dose oral corticosteroid and group 4: placebo. Total follow-up was 22 days after enrolment in the study and the primary outcome was hospital admission up to 7 days after enrolment. The BSC study cohort (total sample size for Ontario and Alberta 724) included infants with bronchiolitis who were either ineligible for CanBEST or those who did not consent to participation in CanBEST. ${ }^{34}$ The baseline data for both studies included clinical, demographic, historical and environmental data. Follow-up data for children in CanBEST included laboratory investigation for viral pathogen, admission to hospital, length of hospital stay and intensive care unit (ICU) admission. The BSC study children received treatment for bronchiolitis following standard guidelines with treatments and outcomes recorded. These data are currently housed in a repository in Ontario, at the Children's Hospital of Eastern Ontario, Ottawa.

Health administrative data: in Ontario, data from the bronchiolitis cohort described above will be linked to six Ontario-based HAD housed and accessible through ICES.
ICES is an independent non-profit research institute whose legal status under Ontario's health information privacy law allows it to collect and analyse healthcare and demographic data, without consent, for health system evaluation and improvment. The following databases will be used: (1) Ontario Health Insurance Plan database, which contains information on all fee-for-service billings for physician services rendered, (2) National Ambulatory Care Reporting System database (NACRS), which contains data for hospital-based and community-based emergency and ambulatory care, (3) Ontario Registered Persons Database, which includes information on demographics and on the time period for which each participant was eligible to receive publicly funded provincial healthcare, (4) Discharge Abstract Database (DAD), which provides information on all acute care hospitalisations; (5) Ontario Asthma Surveillance Information System (OASIS), a validated registry that uses administrative databases to identify and follow individuals with asthma; and (6) MOMBABY database, which contains information from hospital admission records for mothers linked with their newborns at the time of birth. In Alberta, the bronchiolitis cohort will be linked to provincial HAD housed at and accessible through the Enterprise Data Warehouse, maintained by Alberta Health Services (AHS) Analytics. The Enterprise Data Warehouse contains the CIHI DAD, NACRS, Alberta physician claims and Alberta Pharmaceutical Information Network. AHS Analytics has created coding that creates a linked data set of all Alberta mothers and their infants from FY 2002/2003 up to present day. Children's health service utilisation data will be drawn from this linked data set of all Alberta mothers and their infants.

\section{Data linkage and transfer}

Individual records from the bronchiolitis cohort will be deterministically linked to HAD within each province. In Ontario, we will use the unique Ontario health insurance number for linkage and access to data housed at ICES. In Alberta, the Alberta Unique Lifetime Identifier will be used to link and access data in Alberta-based HAD housed in the Enterprise Data Warehouse, AHS. In Alberta, the data set created for these patients will be deidentified and transferred via Services Secure File Transfer Protocol to the secure analytical environment at ICES to create a combined two-province study data set. The linked data sets from the two provinces will then be pooled within the secure analytical environment at ICES to create an Integrated Pediatric Health Data Repository (see online supplemental file 1). While we anticipate a high success rate of linking the bronchiolitis clinical data sets to HAD, it is possible that some children may not be matched due to unavailability of health card number. If we identify a significant number of patients with an unavailable health card number, we will use a probabilistic approach for these patients to link their bronchiolitis clinical trial data to HAD. 


\section{Data storage and analysis}

Once the data have been transferred and linked, it will be retained in the secure environment of ICES. ICES will assign an ICES key number (IKN) for each subject in the linked database. Only the IKN will be provided in the data set containing the various variables for analysis, the Ontario health card number will not be provided. Data analysis will be performed through ICES Data \& Analytic Services.

\section{Outcome measures and predictors \\ Outcome measure}

Our primary outcome is the cumulative incidence of asthma by age 5 and 10 years. We will define asthma using a validated health administrative case definition, which has been shown to have $89 \%$ sensitivity and $72 \%$ specificity to identify asthma in children aged $0-17$ years. ${ }^{48} 49$ Previous studies have used this case definition to identify asthma in the paediatric population, ${ }^{18} 50$ and it has also been used by the Canadian Chronic Disease Surveillance System to identify asthma cases from provincial HAD that includes Ontario and Alberta. ${ }^{51}$

\section{Covariates}

Important covariates (all measured in CanBEST and BSCS) will include clinical risk factors: gestational age at birth, birth weight, age at bronchiolitis diagnosis, infant sex, personal history of atopy, maternal and family history of asthma, smoking exposure (maternal and environmental), breastfeeding, daycare attendance, respiratory distress assessment index (RDAI), receipt of RSV immunoglobulin, presence of comorbidities, type of viral pathogen, disease severity (based on hospital admission or ICU admission) and type and dosage of medications. Socioeconomic status will be measured using the Canadian/Ontario marginalisation index. ${ }^{52}$ We will use HAD to measure: respiratory-related health service use (number of hospitalisations, ED or physician office visits) for acute lower respiratory tract infections (LRTI), total days of hospital admission for acute LRTI and receipt of primary immunisations. Counts for respiratoryrelated health service use will be accrued from the time the child is diagnosed with bronchiolitis until reaching 2 years of age.

\section{Approaches and analysis}

Objective 1: quantify the risk of developing asthma by age 5 and 10 years in children treated with high-dose corticosteroid and epinephrine for bronchiolitis during infancy.

1. Risk estimation: risk of asthma by age 5 and 10 years will be assessed by comparing children diagnosed with bronchiolitis who received high-dose corticosteroid and epinephrine (exposed group, $\mathrm{N}=180$ ) to those who did not receive high-dose corticosteroid and epinephrine for treatment of bronchiolitis (nonexposed group, $\mathrm{N}=1050$ ). The nonexposed group will comprise: (1) children in CanBEST who received only epinephrine or only placebo as treatment and (2) children in the BSC study (none of whom received high-dose corticosteroid treatment). To determine incident asthma by age 5 and 10 years (the primary outcome) of these children, their health service utilisation record will be followed through the HADs. Asthma incidence will be ascertained when the child is of 2 years of age.

2. Statistical analysis: the unadjusted effects of high-dose corticosteroid and epinephrine on later asthma development will be assessed using Cox proportional hazards regression analysis. Because treatment assignment will be nonrandom, we will compare outcomes after controlling for clinical and health service utilisationrelated factors using multivariable adjustment analysis. For our risk-adjusted comparison, multivariable Cox proportional hazards regression modeling will be performed to determine the effect of high-dose corticosteroid and epinephrine after simultaneously adjusting for prespecified risk factors. Adjusted HR with 95\% CI will be generated to estimate the effect of high-dose corticosteroid and epinephrine. Since asthma incidence has been shown to decrease with age, we plan to perform separate analyses for diagnosis of asthma by age 5 and 10 years. ${ }^{1}$

Objective 2: identify risk factors associated with development of asthma by age 5 and 10 years in children diagnosed with bronchiolitis during infancy.

1. Probable risk factors include clinical factors: age at diagnosis of bronchiolitis, sex, RDAI score on ED presentation with bronchiolitis, receipt of RSV immunoglobulin, presence of comorbidities, specific viral pathogen, disease severity (based on hospital admission or ICU admission); early childhood factors (breastfeeding and daycare); environmental factors (tobacco smoke at home); sociodemographic factors and health service utilisation-related factors: respiratory-related health service use (number of hospitalisations, ED or physician office visits) in the 2-year period following bronchiolitis for acute LRTI, total days of hospital admission for acute LRTI and receipt of primary immunisations by age 2 years.

2. Statistical analysis: multivariable Cox proportional hazards regression analysis will be performed to identify significant covariates. Risk estimate of covariates will be presented as adjusted HR with 95\% CI.

Objective 3: develop asthma prediction models for children diagnosed with bronchiolitis during infancy.

1. Prediction modelling: models predicting asthma at age 5 and 10 will be generated using multivariable logistic regression analysis. A forward stepwise method (with entrance tolerances of 0.05 ) will be used to determine significant predictors for inclusion in the regression models. Collinearity and correlation will be analysed before model fitting. We will internally validate our models and assess their predictive accuracy by discrimination (area under the curve) and calibration (by plotting observed vs predicted number of outcomes). Internal validation will be performed using bootstrapping method. ${ }^{53}$ Potential clinical predictors: age $<6$ months at diagnosis of bronchiolitis, sex, high RDAI score on ED presentation with bronchiolitis, receipt 
of RSV immunoglobulin, presence of comorbidities such as congenital heart disease, presence of RSV viral pathogen, severe disease (based on hospital admission or ICU admission), breastfeeding $<3$ months, no daycare attendance, tobacco smoke at home and low socioeconomic status. Potential health service utilisation-related predictors: volume of respiratoryrelated health service use (number of hospitalisations, ED or physician office visits) for acute LRTI $>7$ days of hospital admission for acute LRTI and complete receipt of primary immunisations by age 2 years.

2. Comparison between models developed using only clinical predictors to those developed using both clinical and health service utilisation-related predictors: we will compare the incremental performance of models developed using only clinical variables to those developed using both clinical and health service utilisation-related variables. Incremental improvement in outcome prediction will be determined by examining the change in the area under the receiver-operating characteristic curve, net reclassification index and integrated discrimination improvement. ${ }^{54}$

\section{Study power}

Objective 1: risk of developing asthma by age 5 and 10 years in children treated with high-dose corticosteroid and epinephrine for bronchiolitis during infancy. Evidence has shown in children diagnosed with bronchiolitis during infancy, the proportion of children with asthma between the ages of 5 and 10 years to range from $20 \%$ to $54 \% .^{4-12}$ With 180 subjects in the exposed group (total number of children who received combined therapy of high-dose corticosteroid and epinephrine in CanBEST) and a minimum of 180 subjects in the nonexposed group and assuming an asthma proportion of $35 \%$ in the nonexposed group, we will have $>80 \%$ power to detect an absolute difference in proportion of at least $14 \%$ between the exposed and nonexposed group. A sensitivity analysis showing the power for varying proportions of children with asthma in the exposed group is included in online supplemental file 2.

Objective 3: develop asthma prediction models for children diagnosed with bronchiolitis during infancy. We will use data from CanBEST and BSCS studies ( $\mathrm{N}=1440)$. A well-used 'rule of thumb' for multivariable prediction model sample size is to ensure at least 10 outcome events per predictor before selection of the model. We will follow criteria set by Riley et al to account for minimum overfitting of data. ${ }^{556}$

\section{PATIENT AND PUBLIC INVOLVEMENT}

Patients were not involved in the development of the study research question, outcome methods or design of the study and will not be involved in the conduct of the study.

\section{ETHICS AND DISSEMINATION}

We have received ethics approval of our study from all four sites of the study. ICES is an independent, nonprofit research institute whose legal status under Ontario's health information privacy law allows it to collect and analyse healthcare and demographic data, without consent, for health system evaluation and improvement. As part of our integrative knowledge translation plan, we have consulted clinicians across the spectrum of paediatric care in the development of the study and will continue this consultation at key stages of the study (eg, evaluating results). Our end-of-grant knowledge translation plan includes dissemination of study findings to the academic community, relevant stakeholders and to the public through presentations at international paediatric, emergency medicine and respirology meetings and publication in peer-reviewed journals.

\section{DATA DISPOSITION}

The data set from this study will be held securely in coded form at ICES. While data sharing agreements prohibit ICES from making the data set publicly available, access may be granted to those who meet prespecified criteria for confidential access, available at www.ices.on.ca/DAS. The full data set creation plan and underlying analytic code will be available from the authors on request, understanding that the computer programs may rely on coding templates or macros that are unique to ICES and, therefore, either inaccessible or may require modification.

\section{Author affiliations}

${ }^{1}$ Research Institute, Children's Hospital of Eastern Ontario, Ottawa, Ontario, Canada ${ }^{2}$ ICES, Ottawa, Ontario, Canada

${ }^{3}$ School of Epidemiology and Public Health, Faculty of Medicine, University of Ottawa, Ottawa, Ontario, Canada

${ }^{4}$ Department of Pediatrics, Faculty of Medicine, University of Ottawa, Ottawa, Ontario, Canada

${ }^{5}$ Clinical Epidemiology Program, Ottawa Hospital Research Institute, Ottawa, Ontario, Canada

${ }^{6}$ Departments of Pediatrics and Physiology and Pharmacology, University of Calgary, Calgery, Alberta, Canada

${ }^{7}$ Maternal Newborn Child \& Youth SCN, Alberta Health Services, Calgery, Alberta, Canada

${ }^{8}$ Department of Pediatrics, University of Alberta, Edmonton, Alberta, Canada

${ }^{9}$ Research Institute, The Hospital for Sick Children, Toronto, Ontario, Canada

${ }^{10}$ London Health Sciences Centre, London, Ontario, Canada

Correction notice This article has been corrected since it was published. The trial registration number has been removed from the Abstract as it relates to CanBEST study mentioned under Methods and analysis section of Abstract and not the main article.

Acknowledgements This study was supported by ICES, which is funded by an annual grant from the Ontario Ministry of Health and Long-Term Care (MOHLTC). The opinions, results and conclusions reported in this paper are those of the authors and are independent from the funding sources. No endorsement by ICES or the Ontario MOHLTC is intended or should be inferred.

Collaborators Pediatric Emergency Research Canada: Terry P Klassen; Andrew Dixon; Troy Turner and Rhonda Correll

Contributors KA and ACP co-designed the study, scientific content, obtained funding, developed protocol and study materials, obtained necessary approvals for the study and critically revised this manuscript. DBF and DR contributed to the design, scientific content, contributed to grant application development and review of the manuscript. SH contributed to statistical planning. DWJ, PM, TT, GJ contributed to review of the manuscript.

Funding This work is supported by the Canadian Institute of Health Research (CIHR), grant number (DA5-170276). We also received a grant from the Ontario Thoracic Society for this project. 
Disclaimer The opinions and statements expressed in this material are those of the authors and are not necessarily those of the funding or data sources; no endorsement is intended or should be inferred.

Competing interests None declared.

Patient consent for publication Not required.

Provenance and peer review Not commissioned; externally peer reviewed.

Supplemental material This content has been supplied by the author(s). It has not been vetted by BMJ Publishing Group Limited (BMJ) and may not have been peer-reviewed. Any opinions or recommendations discussed are solely those of the author(s) and are not endorsed by BMJ. BMJ disclaims all liability and responsibility arising from any reliance placed on the content. Where the content includes any translated material, BMJ does not warrant the accuracy and reliability of the translations (including but not limited to local regulations, clinical guidelines, terminology, drug names and drug dosages), and is not responsible for any error and/or omissions arising from translation and adaptation or otherwise.

Open access This is an open access article distributed in accordance with the Creative Commons Attribution Non Commercial (CC BY-NC 4.0) license, which permits others to distribute, remix, adapt, build upon this work non-commercially, and license their derivative works on different terms, provided the original work is properly cited, appropriate credit is given, any changes made indicated, and the use is non-commercial. See: http://creativecommons.org/licenses/by-nc/4.0/.

\section{ORCID iDs}

Kawsari Abdullah http://orcid.org/0000-0003-0535-656X

Teresa To http://orcid.org/0000-0001-7463-3423

\section{REFERENCES}

1 Fauroux B, Simões EAF, Checchia PA, et al. The burden and longterm respiratory morbidity associated with respiratory syncytial virus infection in early childhood. Infect Dis Ther 2017;6:173-97.

2 Wennergren G, Kristjánsson S. Relationship between respiratory syncytial virus bronchiolitis and future obstructive airway diseases. Eur Respir J 2001;18:1044-58.

3 Hall CB. Respiratory syncytial virus: a continuing culprit and conundrum. J Pediatr 1999;135:2-7.

4 Sigurs N, Bjarnason R, Sigurbergsson F, et al. Respiratory syncytial virus bronchiolitis in infancy is an important risk factor for asthma and allergy at age 7. Am J Respir Crit Care Med 2000;161:1501-7.

5 Carbonell-Estrany X, Pérez-Yarza EG, García LS, et al. Longterm burden and respiratory effects of respiratory syncytial virus hospitalization in preterm Infants-The spring study. PLoS One 2015;10:e0125422.

6 Zomer-Kooijker K, van der Ent CK, Ermers MJJ, et al. Increased risk of wheeze and decreased lung function after respiratory syncytial virus infection. PLoS One 2014;9:e87162.

7 Henderson J, Hilliard TN, Sherriff A, et al. Hospitalization for RSV bronchiolitis before 12 months of age and subsequent asthma, atopy and wheeze: a longitudinal birth cohort study. Pediatr Allergy Immunol 2005;16:386-92.

8 Koponen P, Helminen M, Paassilta M, et al. Preschool asthma after bronchiolitis in infancy. Eur Respir J 2012;39:76-80.

9 Fjaerli H-O, Farstad T, Rød G, et al. Acute bronchiolitis in infancy as risk factor for wheezing and reduced pulmonary function by seven years in Akershus County, Norway. BMC Pediatr 2005;5:31.

10 James KM, Gebretsadik T, Escobar GJ, et al. Risk of childhood asthma following infant bronchiolitis during the respiratory syncytial virus season. J Allergy Clin Immunol 2013;132:227-9.

11 Escobar GJ, Masaquel AS, Li SX, et al. Persistent recurring wheezing in the fifth year of life after laboratory-confirmed, medically attended respiratory syncytial virus infection in infancy. BMC Pediatr 2013;13:97.

12 Bacharier LB, Cohen R, Schweiger T, et al. Determinants of asthma after severe respiratory syncytial virus bronchiolitis. J Allergy Clin Immunol 2012;130:91-100.

13 Brunwasser SM, Snyder BM, Driscoll AJ, et al. Assessing the strength of evidence for a causal effect of respiratory syncytial virus lower respiratory tract infections on subsequent wheezing illness: a systematic review and meta-analysis. Lancet Respir Med 2020;8:795-806.

14 Pullan CR, Hey EN. Wheezing, asthma, and pulmonary dysfunction 10 years after infection with respiratory syncytial virus in infancy. $\mathrm{Br}$ Med J 1982;284:1665-9.

15 Mok JY, Simpson H. Outcome of acute lower respiratory tract infection in infants: preliminary report of seven-year follow-up study. Br Med J 1982;285:333-7.
16 McConnochie KM, Roghmann KJ. Wheezing at 8 and 13 years: changing importance of bronchiolitis and passive smoking. Pediatr Pulmonol 1989;6:138-46.

17 Midodzi WK, Rowe BH, Majaesic CM, et al. Early life factors associated with incidence of physician-diagnosed asthma in preschool children: results from the Canadian early childhood development cohort study. J Asthma 2010;47:7-13.

18 Radhakrishnan DK, Dell SD, Guttmann A, et al. Trends in the age of diagnosis of childhood asthma. J Allergy Clin Immunol 2014;134:1057-62.

19 To T, Gershon A, Wang C. Persistence and remission in childhood asthma. Arch Pediatr Adolesc Med 2007;161:1197.

20 Kneyber MCJ MCJ, Steyerberg EW, de Groot R, et al. LongTerm effects of respiratory syncytial virus (RSV) bronchiolitis in infants and young children: a quantitative review. Acta Paediatr 2000;89:654-60.

21 Marlow R, Finn A, Henderson J. Assessing the association between bronchiolitis in infancy and recurrent wheeze: a whole English birth cohort case-control study. Thorax 2019;74:503-5.

22 van Woensel JB, Kimpen JL, Sprikkelman AB, et al. Long-Term effects of prednisolone in the acute phase of bronchiolitis caused by respiratory syncytial virus. Pediatr Pulmonol 2000;30:92-6.

23 Dumas O, Hasegawa K, Mansbach JM, et al. Severe bronchiolitis profiles and risk of recurrent wheeze by age 3 years. J Allergy Clin Immunol 2019;143:1371-9.

24 Gern JE, Busse WW. The role of viral infections in the natural history of asthma. J Allergy Clin Immunol 2000;106:201-12.

25 Garrison MM, Christakis DA, Harvey E, et al. Systemic corticosteroids in infant bronchiolitis: a meta-analysis. Pediatrics 2000;105:e44.

26 Beigelman A, Chipps BE, Bacharier LB. Update on the utility of corticosteroids in acute pediatric respiratory disorders. Allergy Asthma Proc 2015;36:332-8.

27 Fernandes RM, Bialy LM, Vandermeer B, et al. Glucocorticoids for acute viral bronchiolitis in infants and young children. Cochrane Database Syst Rev 2013;6:CD004878.

28 Corneli HM, Zorc JJ, Mahajan P, Majahan P, et al. A multicenter, randomized, controlled trial of dexamethasone for bronchiolitis. $N$ Engl J Med 2007;357:331-9.

29 Plint AC, Johnson DW, Patel $\mathrm{H}$, et al. Epinephrine and dexamethasone in children with bronchiolitis. N Engl J Med 2009;360:2079-89.

30 Ralston SL, Lieberthal AS, Meissner HC, et al. Clinical practice guideline: the diagnosis, management, and prevention of bronchiolitis. Pediatrics 2014;134:e1474-502.

31 O'Brien S, Borland ML, Cotterell E, et al. Australasian bronchiolitis guideline. J Paediatr Child Health 2019;55:42-53.

32 Canadian Paediatric Society. Bronchiolitis: recommendations for diagnosis, monitoring and management of children one to 24 months of age, 2019. Available: https://www.cps.ca/en/documents/position/ bronchiolitis

33 NICE. Overview | bronchiolitis in children: diagnosis and management | guidance. Available: https://www.nice.org.uk/ guidance/ng9 [Accessed 4 Oct 2019].

34 Plint AC, Johnson DW, Correl R. Predicting the development of severe bronchiolitis among an emergency department cohort: a multi-centre study. CJEM 2008;10:26.

35 Newton R, Holden NS. Separating transrepression and transactivation: a distressing divorce for the glucocorticoid receptor? Mol Pharmacol 2007;72:799-809.

36 Kaur M, Chivers JE, Giembycz MA, et al. Long-acting beta2adrenoceptor agonists synergistically enhance glucocorticoiddependent transcription in human airway epithelial and smooth muscle cells. Mol Pharmacol 2008;73:203-14.

37 Holden NS, Bell MJ, Rider CF, et al. $\beta 2$-Adrenoceptor agonistinduced RGS2 expression is a genomic mechanism of bronchoprotection that is enhanced by glucocorticoids. Proc Nat Acad Sci U S A 2011;108:19713-8.

38 Smit HA, Pinart M, Antó JM, et al. Childhood asthma prediction models: a systematic review. Lancet Respir Med 2015;3:973-84.

39 Shinohara M, Wakiguchi $\mathrm{H}$, Saito $\mathrm{H}$, et al. Presence of eosinophils in nasal secretion during acute respiratory tract infection in young children predicts subsequent wheezing within two months. Allergol Int 2008;57:359-65.

40 Wever-Hess J, Kouwenberg JM, Duiverman EJ, et al. Prognostic characteristics of asthma diagnosis in early childhood in clinical practice. Acta Paediatr 1999;88:827-34.

41 Castro-Rodríguez JA, Holberg CJ, Wright AL, et al. A clinical index to define risk of asthma in young children with recurrent wheezing. Am J Respir Crit Care Med 2000;162:1403-6. 
42 Savenije OEM, Kerkhof M, Koppelman GH, et al. Predicting who will have asthma at school age among preschool children. J Allergy Clin Immunol 2012;130:325-31.

43 Lu S, Hartert TV, Everard ML, et al. Predictors of asthma following severe respiratory syncytial virus (RSV) bronchiolitis in early childhood. Pediatr Pulmonol 2016;51:1382-92.

44 Carroll KN, Wu P, Gebretsadik T, et al. The severity-dependent relationship of infant bronchiolitis on the risk and morbidity of early childhood asthma. J Allergy Clin Immunol 2009;123:1055-61.

45 Al-Shawwa B, Al-Huniti N, Abu-Hasan M. Respiratory syncytial virus bronchiolitis and risk of subsequent wheezing: a matter of severity. Pediatr Asthma Allergy Immunol 2006;19:26-30.

46 Kotaniemi-Syrjänen A, Reijonen TM, Korhonen K, et al. Wheezing requiring hospitalization in early childhood: predictive factors for asthma in a six-year follow-up. Pediatr Allergy Immunol 2002;13:418-25.

47 Chen W, Subbarao P, McGihon RE, et al. Patterns of health care use related to respiratory conditions in early life: a birth cohort study with linked administrative data. Pediatr Pulmonol 2019;54:1267-76.

48 To T, Dell S, Dick PT, et al. Case verification of children with asthma in Ontario. Pediatr Allergy Immunol 2006;17:69-76.

49 Gershon AS, Wang C, Guan J, et al. Identifying patients with physician-diagnosed asthma in health administrative databases. Can Respir J 2009;16:183-8.
50 To T, Simatovic J, Zhu J, et al. Asthma deaths in a large provincial health system. A 10-year population-based study. Ann Am Thorac Soc 2014;11:1210-7.

51 Government of Canada. Report from the Canadian chronic disease surveillance system: asthma and COPD in Canada, 2018. Available: https://www.canada.ca/en/public-health/services/publications/ diseases-conditions/asthma-chronic-obstructive-pulmonarydisease-canada-2018.html\#a1.2.1

52 MAP Centre for Urban Health Solutions. Canadian/Ontario marginalization index | research at St. Michael's Hospital [Internet], 2019. Available: http://stmichaelshospitalresearch.ca/ research-programs/urban-health-solutions/resources-and-reports/ canadianontario-marginalization-index/

53 Harrell FE. Regression modeling strategies [Internet]. Vol. 330, BIOS, 2014. Available: http://citeseerx.ist.psu.edu/viewdoc/download?doi= 10.1.1.468.8845\&rep=rep1\&type=pdf

54 Rigatto C, Sood MM, Tangri N. Risk prediction in chronic kidney disease. Curr Opin Nephrol Hypertens 2012;21:612-8.

55 Steyerberg E. Clinical prediction models. A practical approach to development, validation and updating. New York. NY: Springer Science+Business Media, 2010.

56 Riley RD, Snell KI, Ensor J, et al. Minimum sample size for developing a multivariable prediction model: PART II - binary and time-to-event outcomes. Stat Med 2019;38:1276-96. 